\title{
BMJ Open Cohort profile: The prospective study on Chinese elderly with multimorbidity in primary care in Hong Kong
}

\author{
Dexing Zhang (D) , ${ }^{1}$ Regina Wing Shan Sit (D) , ${ }^{1}$ Carmen Wong, ${ }^{1}$ Dan Zou, ${ }^{1}$ \\ Stewart W Mercer, ${ }^{2}$ Marjorie C Johnston (D) , ${ }^{3}$ Samuel Yeung Shan Wong ${ }^{1}$
}

To cite: Zhang D, Sit RWS, Wong $\mathrm{C}$, et al. Cohort profile: The prospective study on Chinese elderly with multimorbidity in primary care in Hong Kong. BMJ Open 2020;10:e027279. doi:10.1136/ bmjopen-2018-027279

- Prepublication history for this paper is available online. To view these files, please visit the journal online (http://dx.doi org/10.1136/bmjopen-2018027279).

Received 16 0ctober 2018 Revised 08 January 2020 Accepted 30 January 2020

Check for updates

(C) Author(s) (or their employer(s)) 2020. Re-use permitted under CC BY-NC. No commercial re-use. See rights and permissions. Published by BMJ.

${ }^{1} J C$ School of Public Health and Primary Care, The Chinese University of Hong Kong, Hong Kong, China

${ }^{2}$ Centre for Population Health Sciences, Usher Institute, University of Edinburgh, Edinburgh, Scotland, UK ${ }^{3}$ University of Aberdeen, Aberdeen, UK

Correspondence to

Dr Samuel Yeung Shan Wong; yeungshanwong@cuhk.edu.hk

\section{ABSTRACT}

Purpose This is an ongoing prospective cohort aiming to examine the biopsychosocial health profiles and predictors of health outcomes of older patients with multimorbidity in primary care in Hong Kong.

Participants From April 2016 to October 2017, 1077 patients aged $60+$ years with at least two chronic diseases were recruited in four public primary care clinics in the New Territories East Region of Hong Kong.

Findings to date After weighting, the patients had 4.1 (1.8) chronic conditions and 2.5 (1.9) medications on average; $37 \%$ forgot taking medication sometimes; $71 \%$ rated their health as fair or poor; $17 \%$ were frail; $73 \%$ reported one $(21 \%)$ or two or more $(52 \%)$ body pain areas; $62 \%$ were overweight/obese; $23 \%$ reported chewing difficulty, $18 \%$ reported incontinence; $36 \%$ had current stage $1 / 2$ hypertension; $38 \%$ had handgrip strength below the cut-off; $10 \%$ screened positive in sarcopenia; $17 \%$ had mild or severer cognitive impairment; $17 \%$ had mild to severe depression; $16 \%$ had mild to severe anxiety; $50 \%$ had subthreshold to severe insomnia; $28 \%$ indicated being Ionely; $12 \%$ needed help in at least one out of the five daily functions and the EuroQoL-5-Dimensions-5-Level index score was $0.81(0.20)$ and its Visual Analogue Scale (VAS) score was 67.6 (14.6). In the past 12 months, 17\% were hospitalised, 92\% attended general outpatient clinics, $70 \%$ attended specialist outpatient clinics and $10 \%$ used elderly daycare centre services, the median out-of-pocket health cost was HK\$1000 (US\$150). Female and male patients showed significant differences in many biopsychosocial health aspects.

Future plans With assessments and clinical data, the cohort can be used for understanding longitudinal trajectories of biopsychosocial health profiles of Chinese older patients with multimorbidity in primary care. We are also initially planning cohort studies on factors associated with various health outcomes, as well as quality of life and healthcare use.

\section{Cohort registration number ChiCTR-0IC-16008477}

\section{INTRODUCTION}

Multimorbidity, defined as patients living with two or more chronic health conditions, is common in primary care. The prevalence is increasing over the last decades as a result of an ageing population and changes in lifestyles, for example, more sedentary lifestyle which

\section{Strengths and limitations of this study}

- This prospective cohort comprehensively examines biopsychosocial health problems encountered by Chinese older patients with multimorbidity in a primary care programme in Hong Kong. As far as we are aware of, very few prospective cohorts specifically cover this population in primary care, and no such prospective cohort exists among Chinese.

- The data could be linked with electronic health records to allow follow-up and examination of longterm outcomes associated with multimorbidity and predictors of those outcomes.

- The limitation was that older adult patients who were male, disabled, very ill, institutionalised or housebounded were less likely to have participated in this study; a few assessments were only conducted within subgroups or added at a later stage; the sample size may limit examinations of potential interactions and factors associated with multimorbidity in some subgroups.

- The baseline health results had been weighted according to the census data. The weighted rates might be an underestimation of the rates among the primary care patients and be close to the rates of the general population.

have increased the risk of obesity, resulting in a higher risk of developing chronic conditions. ${ }^{12}$ A recent systematic review suggests that the prevalence of multimorbidity is high among the elderly ranging from $12.9 \%$ to $95.1 \%$ in different studies. ${ }^{3}$ Multimorbidity is associated with increased disability and depression, reduced quality of life and higher rates of adverse drug consequences. ${ }^{4}$ Multimorbidity also leads to increased primary and secondary health service utilisation, especially unplanned healthcare, as well as reduced life expectancy. ${ }^{5}$ The direct and indirect economic burden associated with multimorbidity is huge. ${ }^{6}$ The annual healthcare costs were $€ 4096.86$ among patients with five or more chronic conditions, which was almost five times more than those who were healthy 


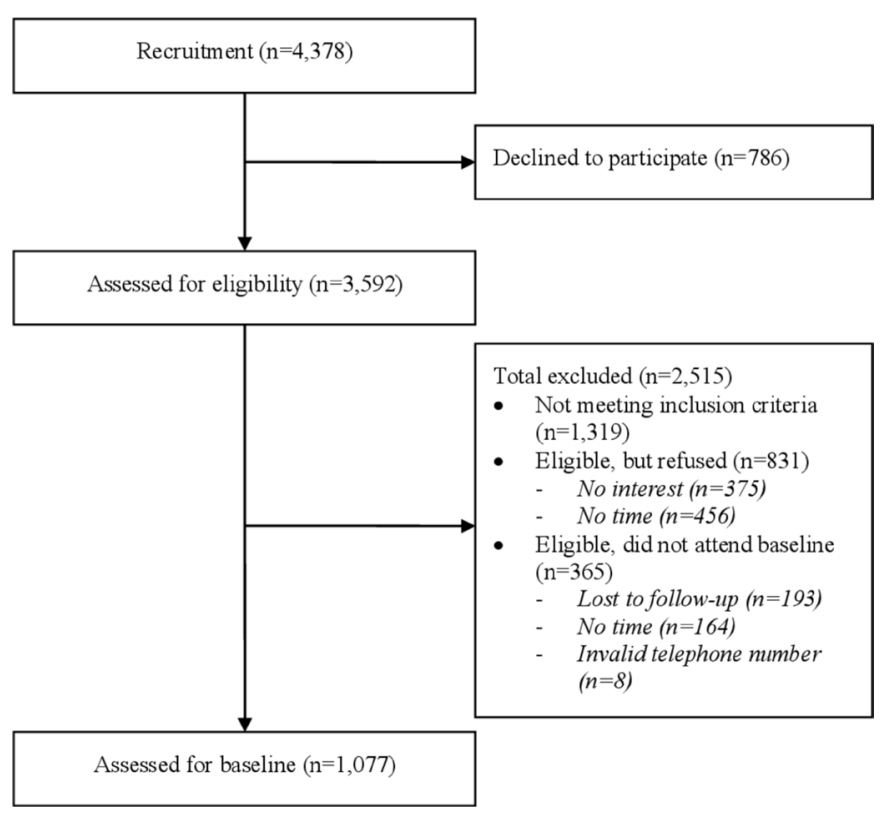

Figure 1 Flow chart of recruitment.

in a study in the West of Ireland. ${ }^{7}$ It has been estimated that by $2030,66 \%$ of the global disease burden will be due to chronic diseases, with most of the burden occurring in the most populous area-Asia. ${ }^{8}$ The economic burden highlights an urgent need for holistic understanding of patients with multimorbidity when searching for costeffective ways to manage these patients, given that treatment of diseases in isolation can be inefficient, leading to duplication of care and poorer health outcomes. ${ }^{10}$

Studies on multimorbidity have increased in recent years, ${ }^{11-20}$ and a clinical guideline on clinical assessment and management of multimorbidity was developed by the National Institute for Health and Care Excellence in the UK in 2016. ${ }^{21}$ However, studies are still needed for the epidemiology and profiles of patients with multimorbidity and their longitudinal outcomes to inform policy-making in different populations including Chinese primary care patients. ${ }^{3} 11$ Most studies on primary care patients with multimorbidity are conducted in western countries such as UK, USA, Australia, Spain and Belgium, ${ }^{14} 15$ 22-28 and limited research has been conducted on psychological and social problems accompanying with multi-

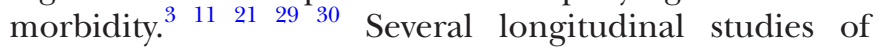
multimorbidity have been conducted in Asian populations, ${ }^{31-33}$ but none of these are of primary care patients. Important knowledge gaps still exist regarding the biopsychosocial health profiles of patients with multimorbidity in primary care among Asian Chinese. ${ }^{34}$ Therefore, more studies among Chinese patients with multimorbidity in primary care are needed to advance our understanding for services. ${ }^{145-39}$

This study focuses on the elderly in Hong Kong, where the population is ageing rapidly. Hong Kong has a population of 7.34 million according to the 2016 census data, with $23.7 \%$ aged 60 years or above. The rate was higher than the proportions in 2006 (16.5\%) and 2011
$(19.5 \%) .{ }^{40}$ In Hong Kong, although there is a large private primary care sector, around $85 \%$ of people with chronic conditions are managed in the public primary care setting. Given that the Hong Kong population has the longest life expectancy in the world: ( 81.7 for men and 87.7 for women in 2017), ${ }^{41}$ the ageing population and multimorbidity have brought much burden and challenge to the local healthcare system. To inform healthcare providers and policy-makers in allocating suitable health services for people with multimorbidity in primary care, the present study aimed to study the longitudinal biopsychosocial health profiles and also predictors of health outcomes of Chinese patients with multimorbidity who present to public primary care in Hong Kong.

\section{COHORT DESCRIPTION \\ Study setting and participants}

This study contains primary care patients from four general outpatient clinics (GOPCs) out of the 10 general outpatient clinics (GOPCs) in the New Territory East Cluster (NTEC), Hong Kong, as permission to recruit from these four clinics was given by the local regulator (the Hospital Authority) during the study period. Each GOPC receives about 450 patients each day. The working hours are generally from 9:00 to 17:00 hours from Monday to Friday with some additional night and weekend sessions. In the most recent Hospital Authority Annual Report 2016-2017, the 10 GOPCs in NTEC provided 972454 consultations in total in the year of $2015 / 2016$, which consisted of one-third of total GOPC consultations in Hong Kong public health system. ${ }^{42}$

The inclusion criteria of participants were: (1) aged 60 years or above; (2) with two or more chronic diseases confirmed by the medical information in the public clinical management system and patients' self-report and (3) could speak and understand Chinese. No specific exclusion criteria were adopted. However, as participants needed to respond to questionnaire surveys and health checks, they should be able to access the clinic, sign informed consent by themselves, and understand and answer the research questions.

Patients were first consecutively screened for eligibility by trained research assistants in the waiting areas of the GOPCs. For those who were eligible, they were asked to provide a contact phone number and then were scheduled to visit the study nurse for further assessments. All patients provided informed consent before participation in the study. From April 2016 to October 2017, 1077 eligible patients were recruited and completed the baseline assessments. The baseline assessments were conducted through face-to-face interviews by nurses or a social worker at a university affiliated primary care clinic. The flow chart of recruitment is shown in figure 1 . The sample size allows a margin of error at $3 \%$ with a $95 \%$ CI. It is also $100 \%$ powered to detect a mean difference of 0.5 (assuming SD is 1.0) and $90 \%$ powered to detect a 
Table 1 Core topic areas in questionnaires and examinations of the study

\section{Assessment \\ Questionnaire}

Use of medication

Compliance of medication use

Depression

Anxiety

Loneliness*

Insomnia

Pain

Physical activity

Self-rated health

Community network

Meaning of existence*

Use of social media

Incontinence*

Frailty*

Sarcopenia*

Cognition

Quality of life

Daily function

Use of health services

Alcohol use

Tobacco use

Caregiving to somebody else

Social economic status

\section{Physical examination}

Blood pressure

Body mass index

Waist circumference

Handgrip strength

\section{Description}

No and duration ( $0-1$ year/2-5years/ $>5$ years) for antihypertensive, cardiovascular and hypolipidaemic drugs, antidiabetics, antipsychotics and analgesics.

'At times, do you forget to take your prescription medications?' (no/yes)

The 2-item Patient Health Questionnaire (PHQ-2) for depression; The 9-item PHQ (PHQ-9) for those with $\mathrm{PHQ}-2 \geq 3$.

The 2-item Genralised Anxiety Disorder (GAD-2); The 7-item GAD (GAD-7) for those with GAD$2 \geq 3$.

The 6-item De Jong Gierveld Loneliness Scale; and one question asking 'Do you feel lonely? (yes/no)' (added at a later stage)

The 7-item Insomnia Severity Index for those answered yes to the screening question 'In the past 2 weeks, do you have insomnia? (yes/no)'

A screening question of 'In the past year, do you have musculoskeletal pain for at least 3 months', for those who answered 'yes, one pain area or 'yes, two or more pain areas', Brief Pain Inventory was measured.

For those were screened positive in pain, Physical Activity Scale for the Elderly was measured. 'In general, how will you describe your health? (extremely good, very good or good/fair/poor)'

'When you need help, do you have someone who is willing to and able to meet your needs?' (always/sometimes/never)

One item extracted from the validated reliable Chinese Purpose in Life test: "My personal existence is utterly meaningless and purposeless vs. very meaningful and purposeful", assessed by a 7-point Likert scale with 1 denoting the lowest level and 7 denoting the highest level of perceived meaning of existence.

A screening question of 'In the past 2 weeks, have you ever used the following social media', for those who answered yes to any of the social media, they were further assessed with importance and comfort of using internet.

'Do you have any difficulty when biting or chewing foods (even with the use of denture)' (yes/ no)

'Do you have incontinence?' (yes/occasionally/no)

The Edmonton Frail Scale.

The 5-item Sarcopenia Assessment.

Mainly assessed with Montreal Cognitive Assessment Hong Kong version but in an earlier stage, Abbreviated Memory Inventory for Chinese was used.

The EQ-5D-5L

Instrumental Activities of Daily Living including ability to use telephone, mode of transportation, shopping, food preparation, ability to handle finances.

Visits to primary care doctors, specialist outpatient clinics, admission to hospital, use of services in elderly daycare centres and out-of-pocket healthcare cost both in private and public in the past year.

The 3-item Alcohol Use Disorders Identification Test-consumption for those who drank alcohol in the past year.

One question asking for current, ex-smoking and non-smoking behaviour.

'Are you taking care of somebody?' (yes/no)

Age, gender, marriage, living status, employment, receiving of social welfare scheme.

Measured twice in $15 \mathrm{~min}$ after rest. 
Table 1 Continued

Assessment Description

Electronic health record and

self-report data

Chronic diseases

43 common chronic conditions in 15 categories including:

1. Metabolic diseases (hypertension, lipid disorder, diabetes).

2. Cancer.

3. Disease of the cardiovascular system (coronary heart disease, stroke/cerebrovascular disease, peripheral vascular disease).

4. Disease of the respiratory system (COPD, bronchiectasis, asthma, chronic pharyngitis / laryngitis).

5. Disease of the liver, spleen and gallbladder (gallbladder/spleen disease, viral hepatitis, chronic liver disease).

6. Disease of the stomach and intestines (dyspepsia and gastritis, diverticular disease of intestine, chronic enteritis; irritable bowel syndrome; constipation).

7. Disease of the musculoskeletal and connective tissue (chronic pain needing medication control, skeletal and connective tissue inflammation (such as arthritis, gout)).

8. Disease of the genitourinary system (chronic kidney disease (nephritis), prostatitis, benign prostatic hyperplasia).

9. Disease of the ear, nose and throat (chronic rhinitis, deafness/tinnitus).

10. Disease of the visual system (glaucoma/cataracts, blindness/amblyopia, diabetic eyes, retinal detachment).

11. Disease of the skin (eczema, psoriasis).

12. Disease of the blood (anaemia).

13. Disease of the nervous system (multiple sclerosis, migraine, epilepsy, Parkinson's disease).

14. Mental disorders (schizophrenia/bipolar disorder, depression, anxiety and other stressrelated disorders, dementia).

15. Others.

Use of medication

Medication use number and duration ( $0-1$ year $/ 2-5$ years $/>5$ years) for antihypertensive drugs, cardiovascular drugs, cholesterol-lowering drugs, antidiabetics, antipsychotics and analgesics

*Measures were added at later stages: about 712-995 patients received these measures.

COPD, Chronic obstructive pulmonary disease; EQ-5D-5L, EuroQoL-5-Dimensions-5-Level.

difference of $8 \%$ of different rates, with a follow-up rate of $50 \%(\alpha=0.05) .{ }^{43} 44$

\section{Measures}

The assessments covered a range of measures that are postulated to be potential physical, psychological and social factors associated with multimorbidity. Each complete assessment lasted for about $45-60 \mathrm{~min}$. All the measures were validated and have been widely used or have been used in our previous studies. Information was collected through face-to-face interviews by trained nurses, social workers and research assistants, and additional information of the disease entities, medication use and health service utilisation was confirmed through the review of electronic medical records by nurses. The electronic medical records include patient information and diagnosis, health examinations, medication prescription and health visits to the public health system. The records cover all patients who seek medical services in public health system. It is a medical record system of routine clinical practices with quality ensured by all healthcare professionals including trained doctors, nurses and allied health professionals under Hospital Authority in Hong Kong.
The measures in the questionnaires included: (1) the number and type of chronic diseases in fifteen categories (a total of 43 chronic conditionals) adapted slightly by a group of family physicians and researchers based on chronic conditions employed in previous studies ${ }^{4546}$ and the International Statistical Classification of Diseases 11. Details can be seen in table 1; (2) depression (screened by the 2-item Patient Health Questionnaire (PHQ-2)). ${ }^{47}$ Those with a score of 3 or more (which suggests depression) were further measured by the 9-item PHQ (PHQ-9) ${ }^{48}$; (3) anxiety (screened by the 2-item Generalised Anxiety Disorder (GAD-2)). Those with a score of 3 or more (which suggests anxiety) were further measured by the 7-item GAD (GAD-7) ${ }^{49}$; (4) loneliness (measured by the 6-item De Jong Gierveld Loneliness Scale), ${ }^{50}$ as well as one loneliness question; (5) insomnia (measured by the 7-item Insomnia Severity Index ${ }^{51}$ among those who answered yes to a screening question); (6) pain (measured by the Brief Pain Inventory among those who were screened positive in pain); (7) physical activity (measured by Physical Activity Scale for the Elderly (PASE) ${ }^{52}$ among those who were screened positive in pain); (8) frailty (measured by the Edmonton Frail Scale ${ }^{53}$ which was translated and back-translated by experienced bilingual translators); (9) 
meaning of existence (measured by one question extracted from the validated Chinese Purpose in Life test which was used in a previous study) $)^{54}$; (10) sarcopenia (measured by the 5 -item Sarcopenia Assessment ${ }^{55}{ }^{56}$; (11) cognition (measured by the Hong Kong Montreal Cognitive Assessment (HK-MoCA) with a score of 22 or above being with normal cognition) $)^{57}$; (12) alcohol use (screened by one question and then measured by the 3-item Alcohol Use Disorders Identification Test-consumption for those who screened positive); (13) smoking (non-smoker, current smoker, ex-smoker); (14) medication use (number and duration (0-1 year/2-5years $/>5$ years) of antihypertensive, cardiovascular and hypolipidaemic drugs, antidiabetics, antipsychotics and analgesics was checked in electronic medical system, and compliance of medication use was measured by 'At times, do you forget to take your prescription medications?' (no/yes)); (15) selfrated health; (16) community network; (17) use of social media (measured by a screening question, and for those who answered yes to any of the social media, they were further assessed on the importance and comfort of using the internet); (17) oral health; (18) incontinence; (19) caregiving to somebody; (20) quality of life (measured by the EuroQoL-5-Dimensions-5-Level (EQ-5D-5L) $)^{58}$; (21) daily function (ability to use the telephone, mode of transportation, shopping, food preparation, ability to handle finances were measured); (22) health service utilisation (visits to primary care doctors, specialist outpatient clinics (SOPC), admission to hospital, use of services in elderly daycare centres and out-of-pocket healthcare costs which were not covered by public health system or insurance both in private and public in the past year). In addition, physical examinations included blood pressure, body mass index (BMI), waist circumference and handgrip strength $(\mathrm{kg})$. For blood pressure, two assessments were taken by the nurses. Patients sat for at least 5 min before the first assessment, and they were assessed again $15 \mathrm{~min}$ later. Handgrip strength was also assessed twice for each hand. Social economic status, such as age, gender, marriage, living status, employment, receiving of social welfare scheme, was also included. Due to the data collection plan amendments, a few measures were only collected in a subgroup of the patients at a later stage. Summaries of the baseline measures are described in table 1 .

The questionnaire was set up in password protected EpiData files in a password-protected computer with quality control. For example, for scale questions with answers on a Likert scale of 1-5, a range of 1-5 and one digit was set up so no other results were allowed during data entry. Additionally, for most data variables, a 'must enter' was set up, so that the question could not be missed unless answered or an individual purposely moves to the next question. Checking for missing data was done regularly by experienced researchers and missing data was further collected by nurses through face-to-face interviews, telephone or by checking the electronic medical record system.

\section{Patient and public involvement}

The research questions and outcome measures were developed based on some most common problems that are widely recognised among elder patients. Patients or the public did not involve in the design of the study, recruitment or conduction of the study. The results of the study would be disseminated to patients once he or she requests so and aggregated data would be reported in project reports and research publications and conferences.

\section{Findings to date}

Baseline characteristics of the patients in the study are shown in table 2. The weighted data are shown in the bracket beside the unweighted data. The mean age of the study patients was $70(\mathrm{SD}=6.8)(70.5, \mathrm{SD}=7.9)$ years, $70 \%(53 \%)$ were female, $67 \%(68 \%)$ were married, $14 \%$ $(15 \%)$ lived alone, $92 \%(87 \%)$ were retired or housewives, $49 \%(52 \%)$ had 6 years of education or above, $10 \%$ $(10 \%)$ were on the Comprehensive Social Security Assistance scheme which is open for those with a low income, about half used social media in the last 2 weeks, about $18 \%$ $(15 \%)$ provided care to another (such as their spouse or children/grandchildren), 13\% (17\%) had drank alcohol in the past year and 3\% (4\%) were current smokers. More female patients lived alone, were retired/housewives, had lower education and more received social security support than male patients ( $\mathrm{p}$ values $<0.05$ ).

After weighting, overall, the mean number of chronic diseases was $4.1(\mathrm{SD}=1.8)$ and about one in five patients had six or more chronic diseases. The top three chronic conditions were hypertension $(75 \%)$, dyslipidaemia $(46 \%)$, and skeletal and connective tissue inflammation (eg, arthritis) (36\%). The unweighted and weighted prevalence of comorbidities of the 15 disease categories among the patients is shown in figures 2 and 3, respectively. The unweighted and weighted comorbidities of top 10 prevalent conditions out of the 43 conditions are shown in figures 4 and 5 , respectively, with the combination of hypertension and dyslipidaemia being the most common (39\%), followed by hypertension and diabetes mellitus (27\%), hypertension and skeletal and connective tissue inflammation (eg, arthritis) (26\%), dyslipidaemia and diabetes mellitus (21\%), hypertension and chronic pain $(20 \%)$. Information of the rest comorbidities is shown in the figures. Female patients had fewer number of chronic conditions, fewer number of medications in use but poorer self-rated health than male patients $(\mathrm{p}<0.05)$. On average, patients took $2.5(\mathrm{SD}=1.9)$ medications, with $30 \%$ taking five or more medications regularly, $36 \%$ reported forgot taking medication sometimes.

After weighting, the mean BMI was $24.3(\mathrm{SD}=3.4)$ with $62 \%$ being overweight or obese. Based on the Edmonton Frail Scale, $17 \%$ were frail. Ten per cent had sarcopenia, 23\% reported chewing difficulty, $17 \%$ reported incontinence, $36 \%$ had stage one or two hypertension currently according to the physical examination, 38\% had their handgrip strength (based on the best outcome 


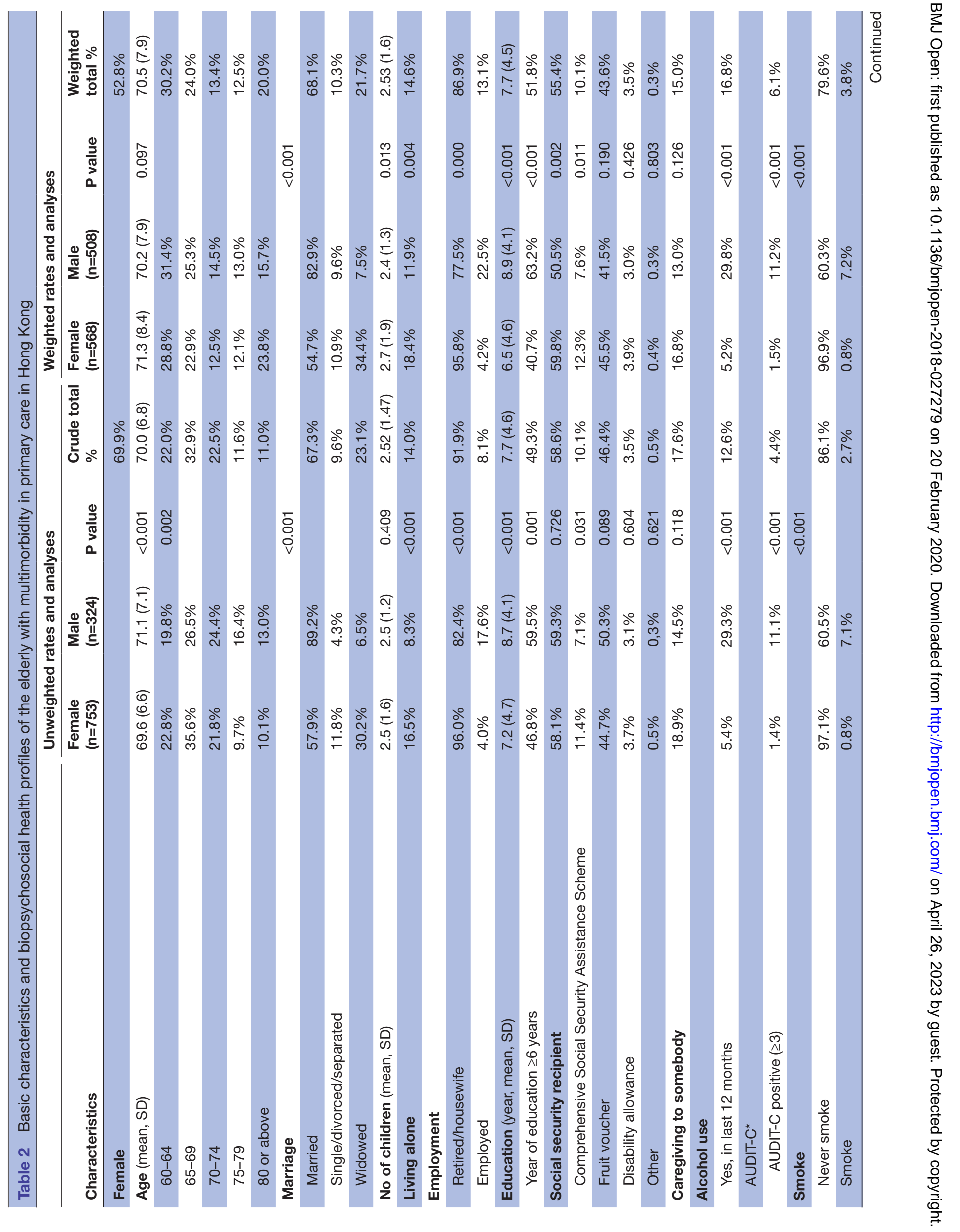




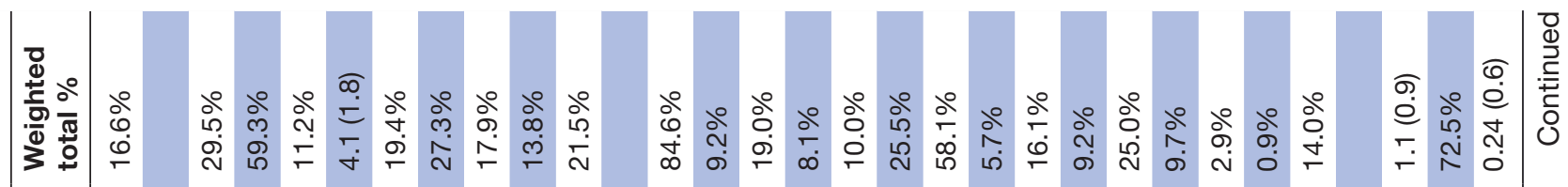

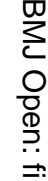

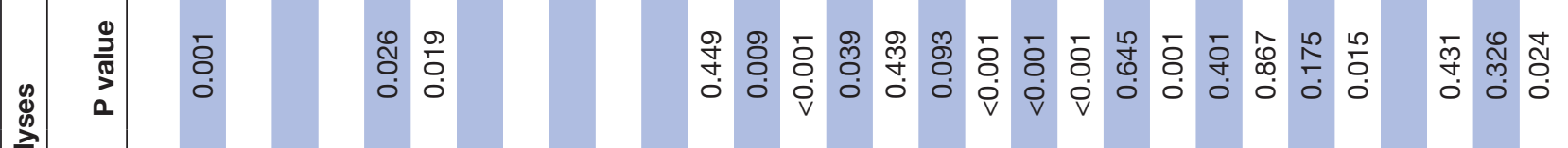

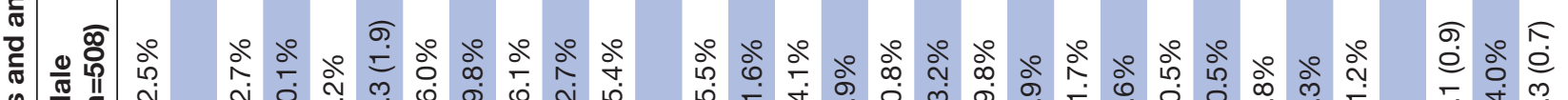
$\stackrel{\text { \& }}{ \pm}$

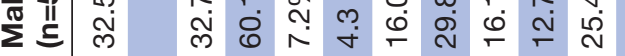
ம்

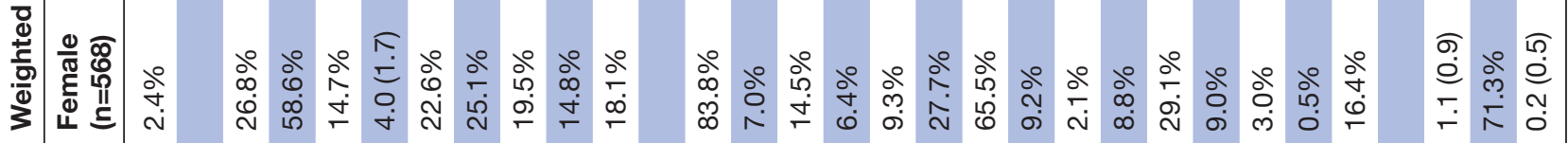

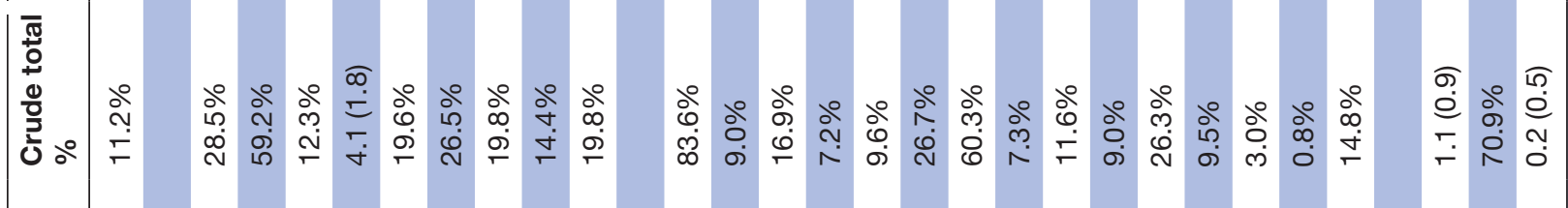

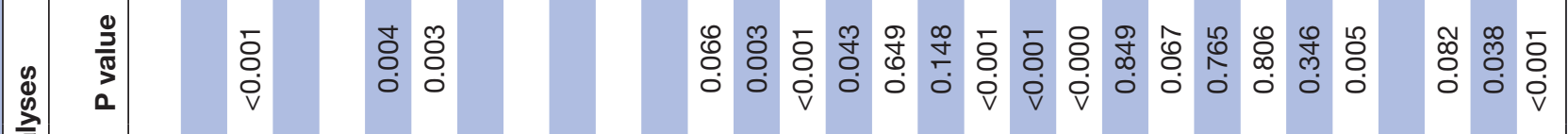
ส

。

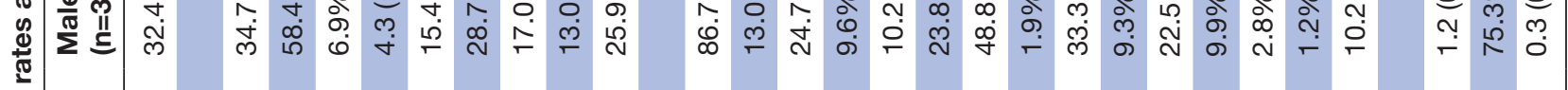

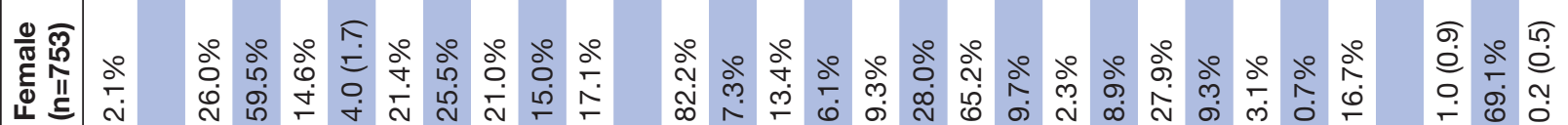

ळ

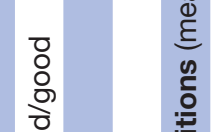

要 
o

ล̀

닌

กำ

i

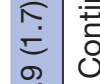

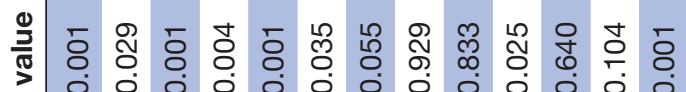

চ্்

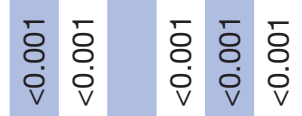

㐫



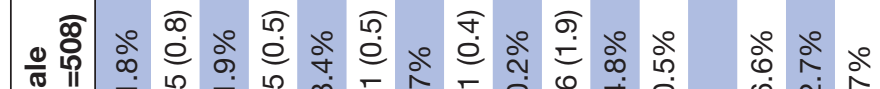

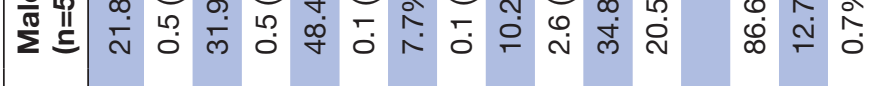

ㅇํㅇำ

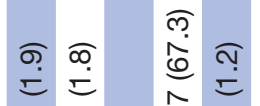

ป 0 0

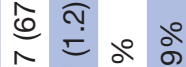

ำ

ம்

$\underset{⿱ ㇒}{\mathscr{E}}$

选

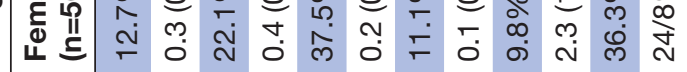

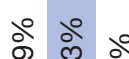

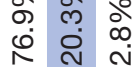

苛

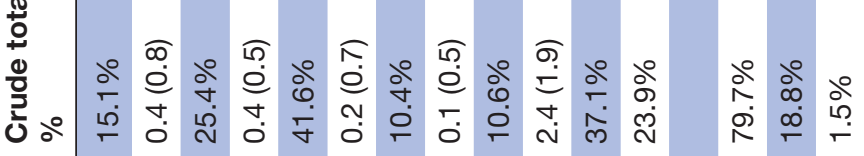

숭

ธิ ล $\widetilde{F}$

$\stackrel{\infty}{\infty} \underset{0}{0}$

ก บ

फ்

웅

$\stackrel{\infty}{\infty}$ de

Y.

$\stackrel{乛}{\check{E}}$

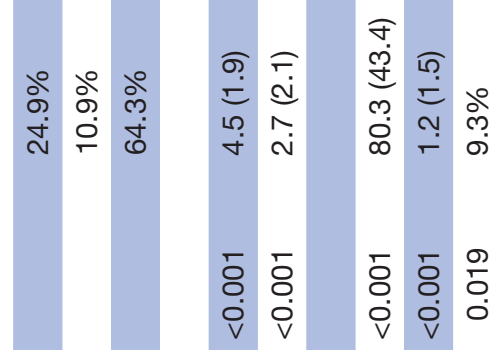

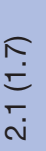

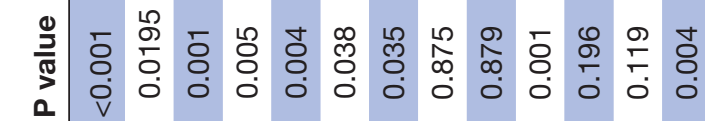

คำ

๑

10

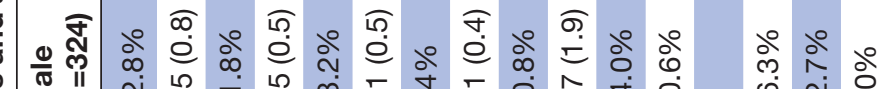
ఖ

ले ले ळ

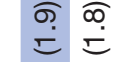

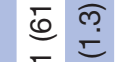

זั N

ळ.

$\underset{\oplus}{\mathscr{E}}$

产

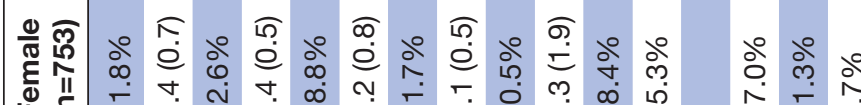

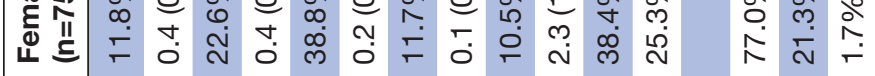

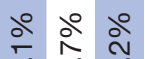

ส กิ

ชี

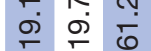

ㄸำ

घं

๖ं

ᄀ ट वे å

Е 人

ஜூ

बิ

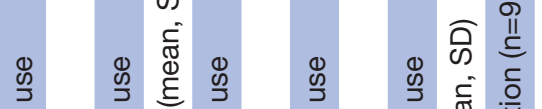

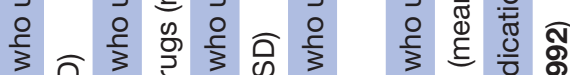

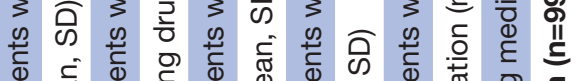

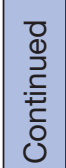

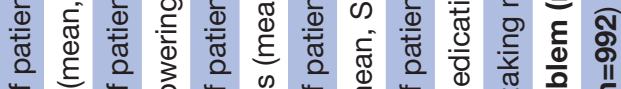
भु

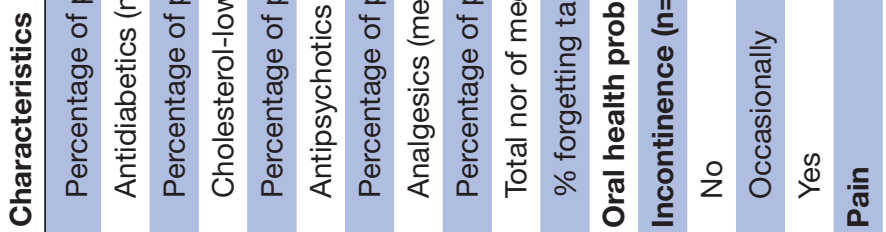

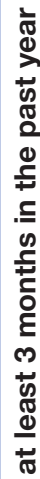

高

ชั

( 


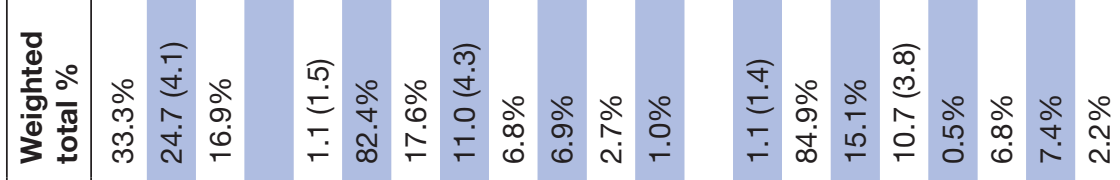

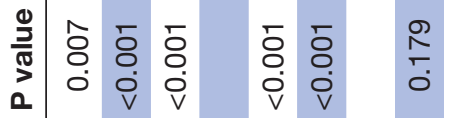

$\frac{\bar{\sigma}}{\frac{\pi}{\pi}}$

它

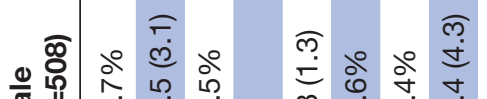

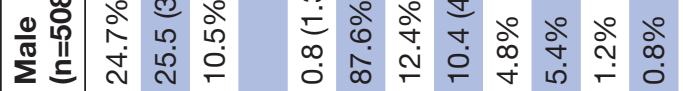

苂

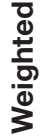

.

$\bar{\infty}$

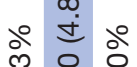

$\frac{1}{2}$

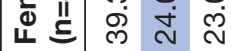

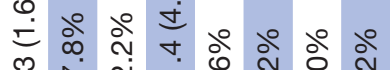

要

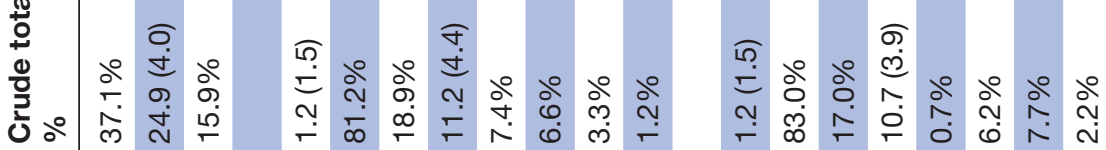

$\begin{array}{lll}\overline{8} & \overline{8} & \text { N } \\ \dot{0} & 0 \\ \text { V } & \text { v }\end{array}$

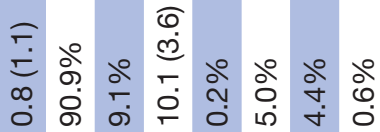

ब

동 ㅇำ

西 否

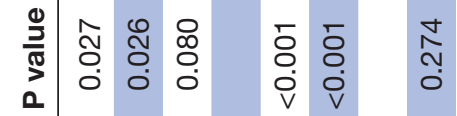

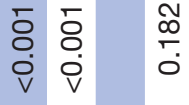

垔

要

离

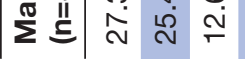

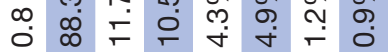

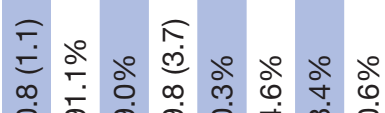

잉

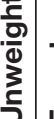

$\frac{0}{\pi}$ ल

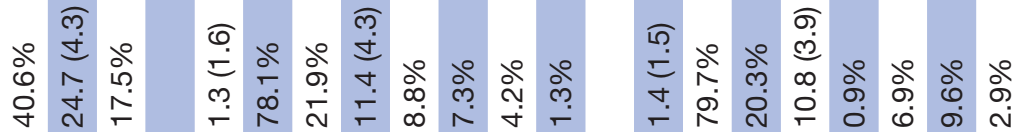

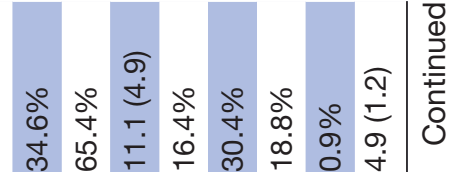

$\mathscr{0}$
$\stackrel{0}{0}$
0

$\overline{8}$

กิ๊

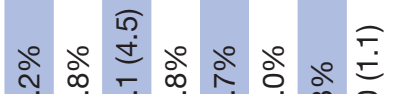
ले đู่

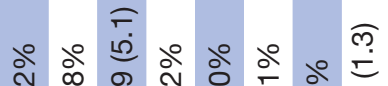

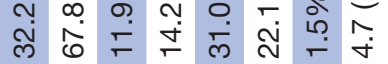

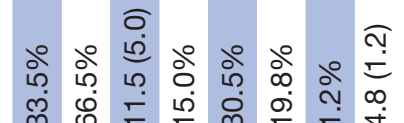

ס्ठ

$\overline{8}$
$\dot{0}$
$\mathrm{v}$

$\infty$
$\stackrel{\circ}{\circ}$
0

๗ั) 㐫

ํำ ㅇำ लं

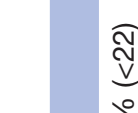

雨 $\frac{\text { व }}{9}$

为

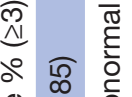

$\stackrel{2}{\stackrel{\infty}{1}}$

西

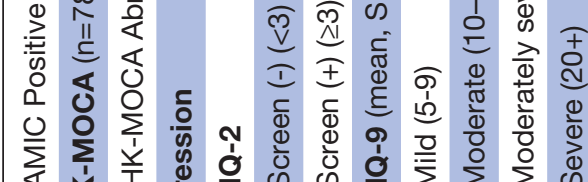

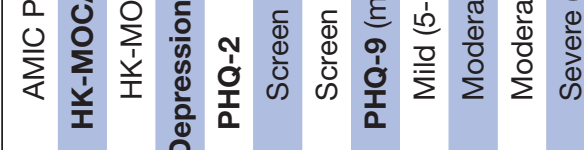

के

की

है है

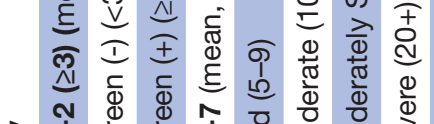

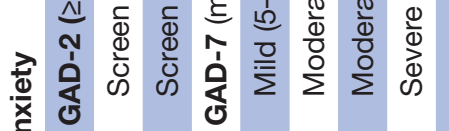

$\frac{0}{3}$

8

$\overrightarrow{\mathrm{F}}$

$\frac{\bar{c}}{\frac{\bar{c}}{\bar{D}}}$

œ

$\vec{\circ}$

$\overrightarrow{\vec{\omega}}$

흥.

ก̀

$\stackrel{0}{\circ}$

N

ชิ

N

ग]

N

○

产

Оे

혹

吾

흥.

$\stackrel{10}{3}$

모․

옥

일

을

N

N

ত

c

$\stackrel{\Phi}{\circledR}$

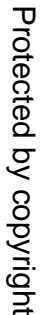




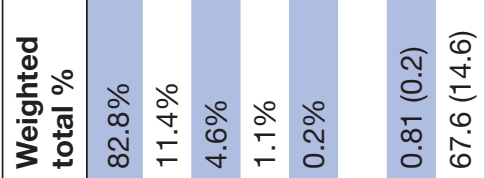

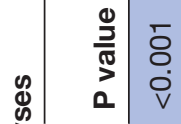

旅

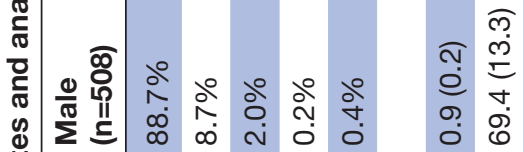

진

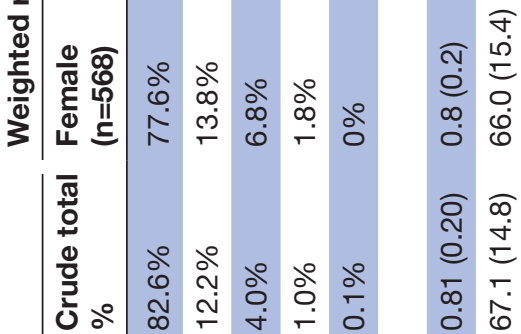

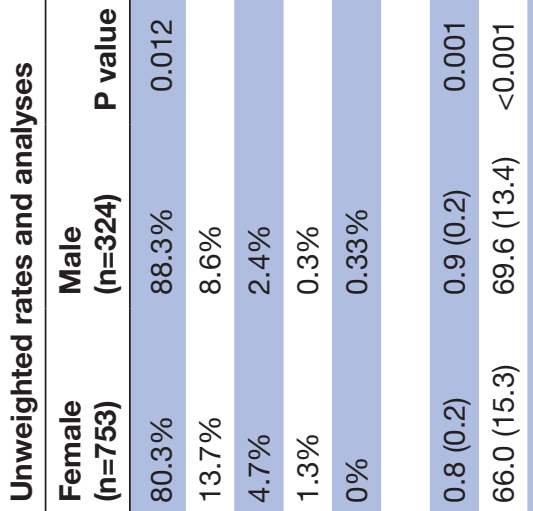

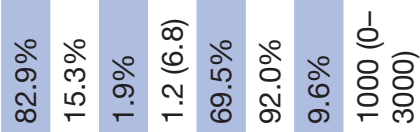

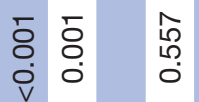

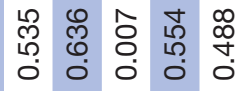

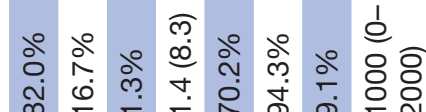

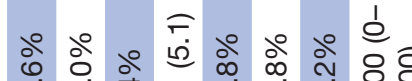

œ

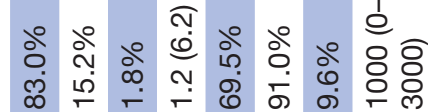

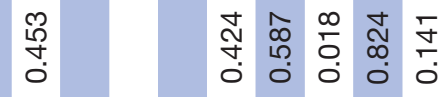

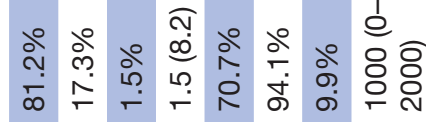

ठิ

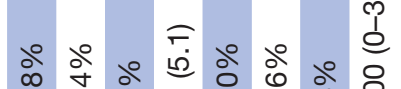
ळ

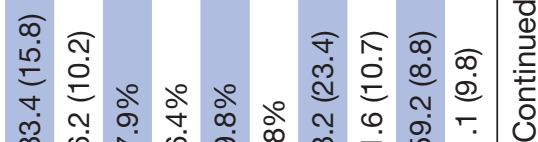

Mํ.

$\begin{array}{lll}\infty & \overline{0} & 0 \\ \infty & 0 & 0 \\ 0 & 0 & 0 \\ 0 & 0 & 0\end{array}$

¿.

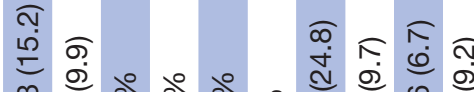

m.

ஸ

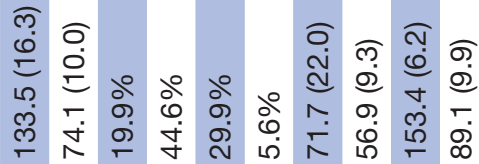

กิ

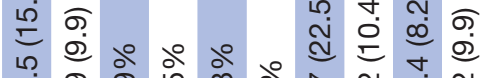

号

仓ึ

$\div \bar{\circ} \bar{\varnothing} \overline{0}$

बิ่ $\widehat{0}$

O. $\widehat{0} \underset{0}{\mathbb{R}} \widetilde{0}$

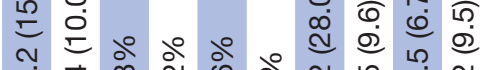

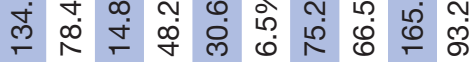

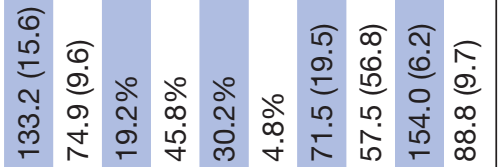

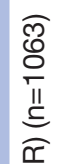

నุ

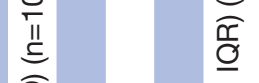

र

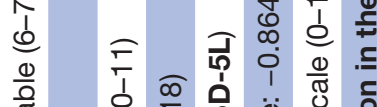

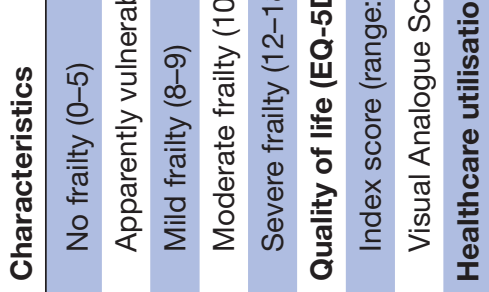

बุ ஓ ᄋ 家

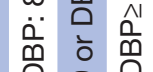

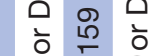

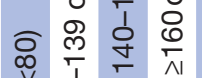

v

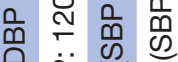

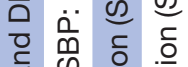




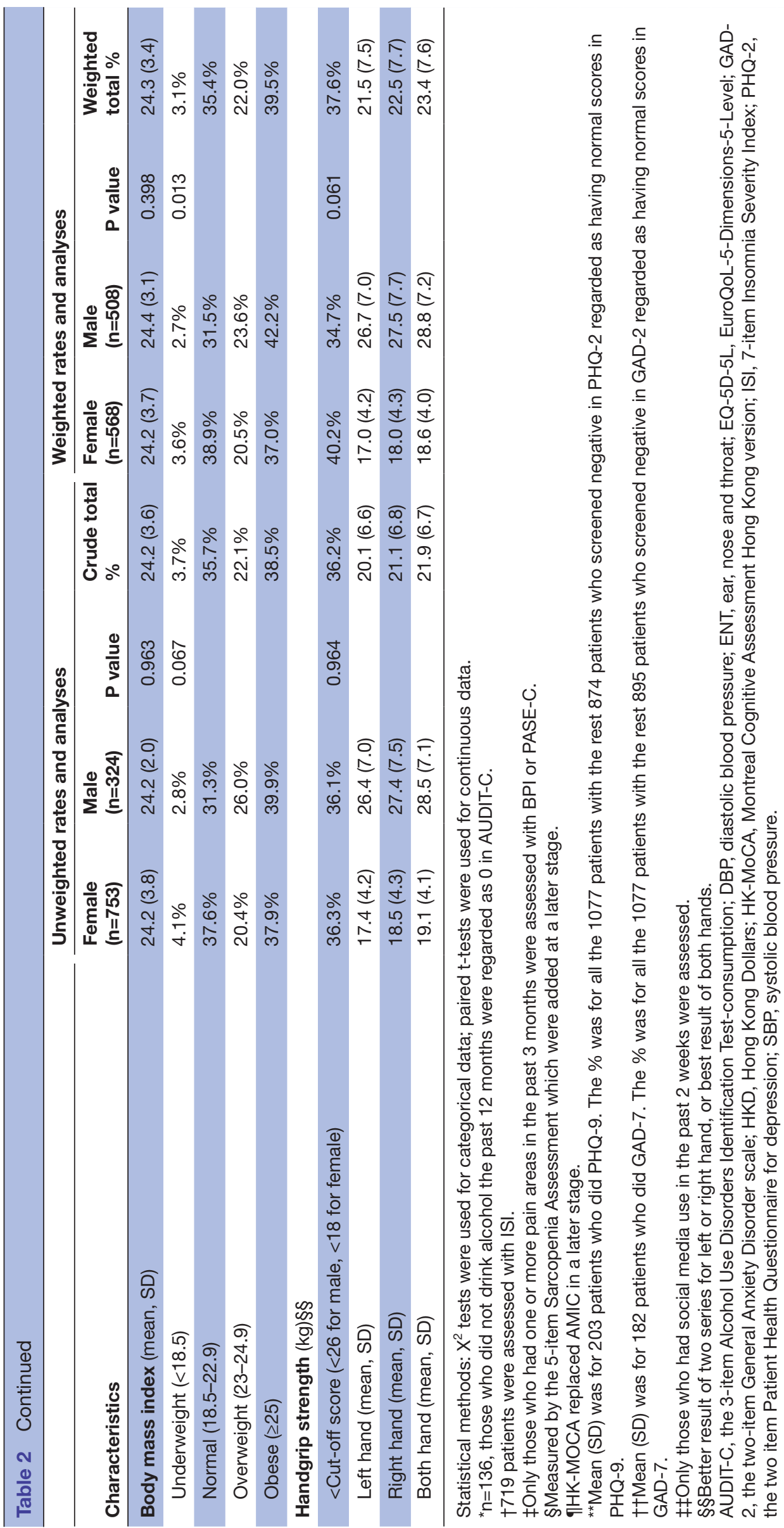




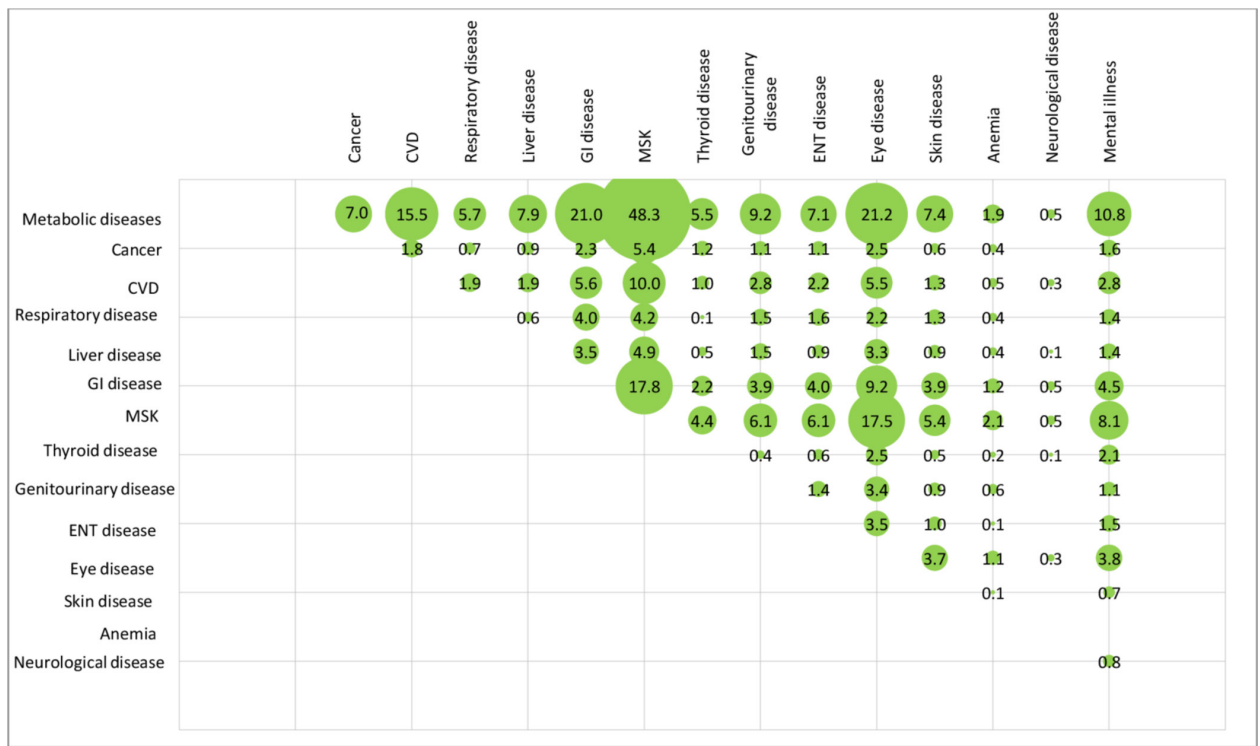

Figure 2 Unweighted prevalence of comorbidities (by 15 disease categories) among the 1077 elderly with multimorbidity (figures are unweighted (\%)). CVD, cardiovascular disease; ENT, ear, nose and throat; Gl disease, gastrointestinal disease; MSK, musculoskeletal disorders.

of two trials of both hands) below the cut-off point, $12 \%$ needed help or were dependent in at least one out of the five daily functions (using telephone, transportation, shopping, preparing meals or financial management). Overall, $30 \%, 59 \%$ and $11 \%$ of patients rated their health being 'excellent/very good/good', 'fair' or 'poor', respectively. Seventy-three per cent reported the presence of one $(21 \%)$ or two or more $(52 \%)$ body pain areas, $17 \%$ scored the HK-MoCA $<22$ suggesting at least mild cognitive impairment; $18 \%$ had PHQ-2 $\geq 3$, while $17 \%$ had PHQ-9 $\geq 5$ suggesting mild depression or more severe; $15 \%$ had GAD- $2 \geq 3$, while $16 \%$ had GAD-7 $\geq 5$ suggesting mild anxiety or more severe; $50 \%$ had insomnia at subthreshold level or above, the mean score of the meaning of existence was $4.9(\mathrm{SD}=1.2)$ out of 7 , $28 \%$ reported feeling lonely. More finding details can be seen in table 2. More female patients had incontinence, pain, sarcopenia and cognitive impairment than male patients. Female patients were more likely to be screened positive in depression and anxiety, reported severer level of insomnia and reported lower perceived existence of meaning than male patients. Female patients were more likely to be frail. More male patients used social media $(\mathrm{p}<0.05)$. The loneliness level and perceived social support were not significantly different between female and male patients.

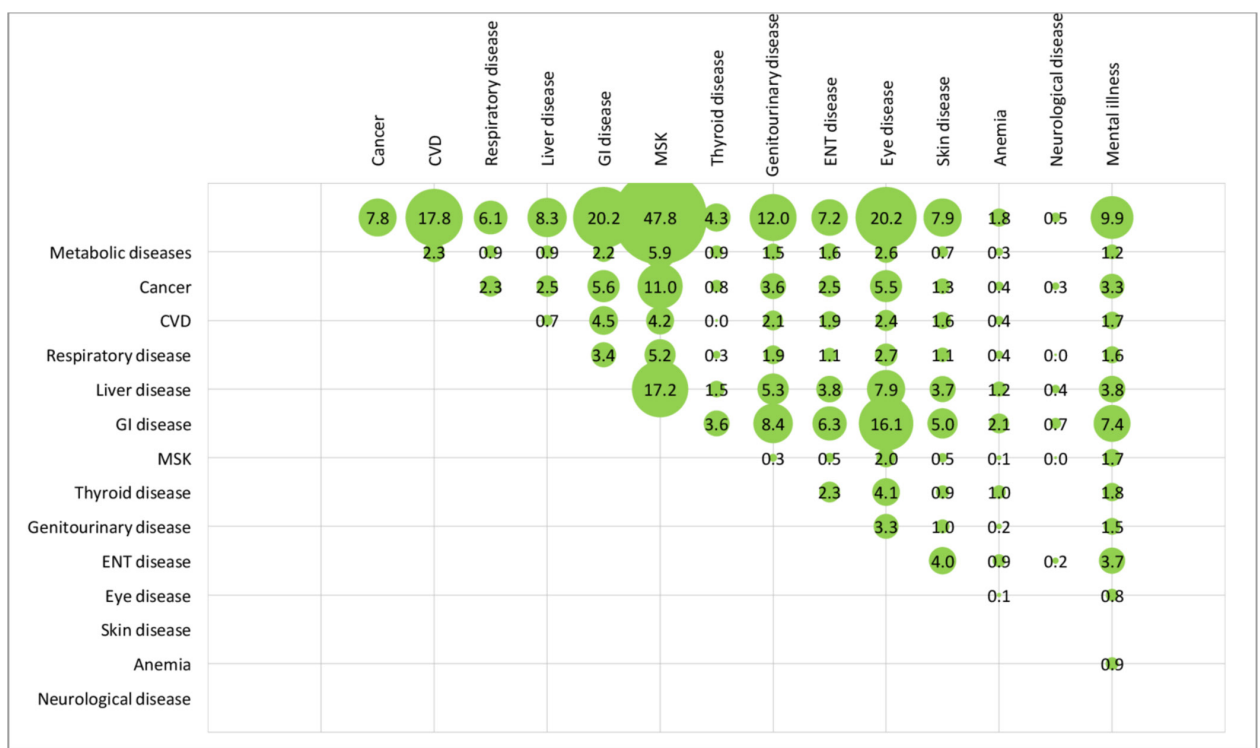

Figure 3 Weighted prevalence of comorbidities (by 15 disease categories) among the 1077 elderly with multimorbidity (figures are weighted prevalence (\%)). CVD: cardiovascular disease; ENT, ear, nose and throat; Gl disease: gastrointestinal disease; MSK: musculoskeletal disorders. 


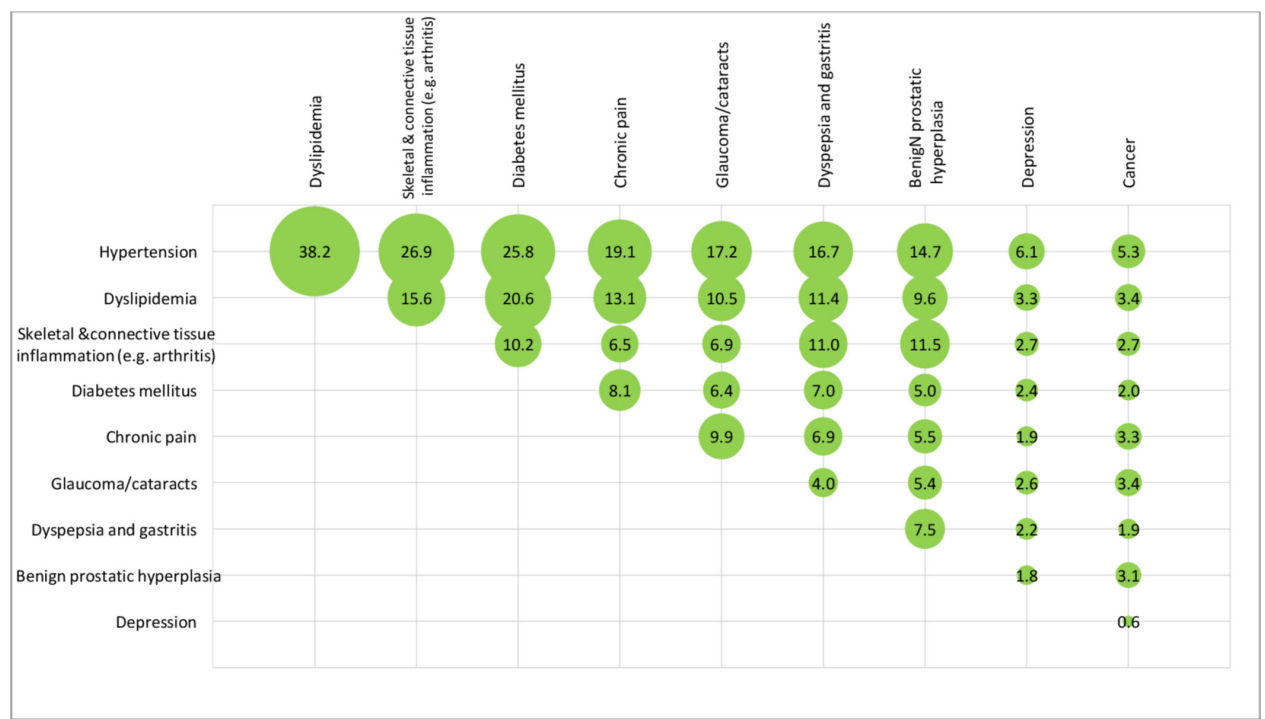

Figure 4 Unweighted prevalence of the comorbidities of top 10 chronic conditions (out of 43 specific chronic conditions) among the 1077 elderly with multimorbidity (figures are unweighted prevalence (\%)).

In addition, after weighting, the EQ-5D-5L index score was $0.81(0.20)$ and its Visual Analogue Scale score was 67.6 (14.6) out of 100. Female patients showed poorer quality of life. In the last year, $17 \%$ were admitted to hospital, 92\% attended GOPG, 70\% attended SOPC, $10 \%$ used elderly day care centre services and the median out-of-pocket health cost was HK\$1000 (US\$150) for any health expenditures not covered by the public health system or insurance. Male patients reported more GOPC visits than female patients in the past year $(\mathrm{p}=0.007)$.

\section{Future plans}

The patients will be followed up regularly (interval of $\sim 2$ years) to monitor changes in health status and outcomes through data collected from questionnaires, physical assessments and clinical records. Key biopsychosocial assessments such as depression, anxiety, loneliness, pain, frailty, as well as quality of life would be included in the follow-up assessments, but each follow-up might be added with some additional assessments with specific research interests. The first follow-up (ie, wave 2 assessment) had started in early 2018. Additional information on mobility by the $30 \mathrm{~s}$ chair-stand test, visual acuity by Amsler Grid test and hearing by Weber's test and Rinne Test were added. Information on electronic medical records will also be updated to provide information on health service utilisation, changes in medication use and new onset of diseases and death.

The longitudinal trajectories of biopsychosocial health profiles of these primary care patients will be described. For example, changes and occurrence of different

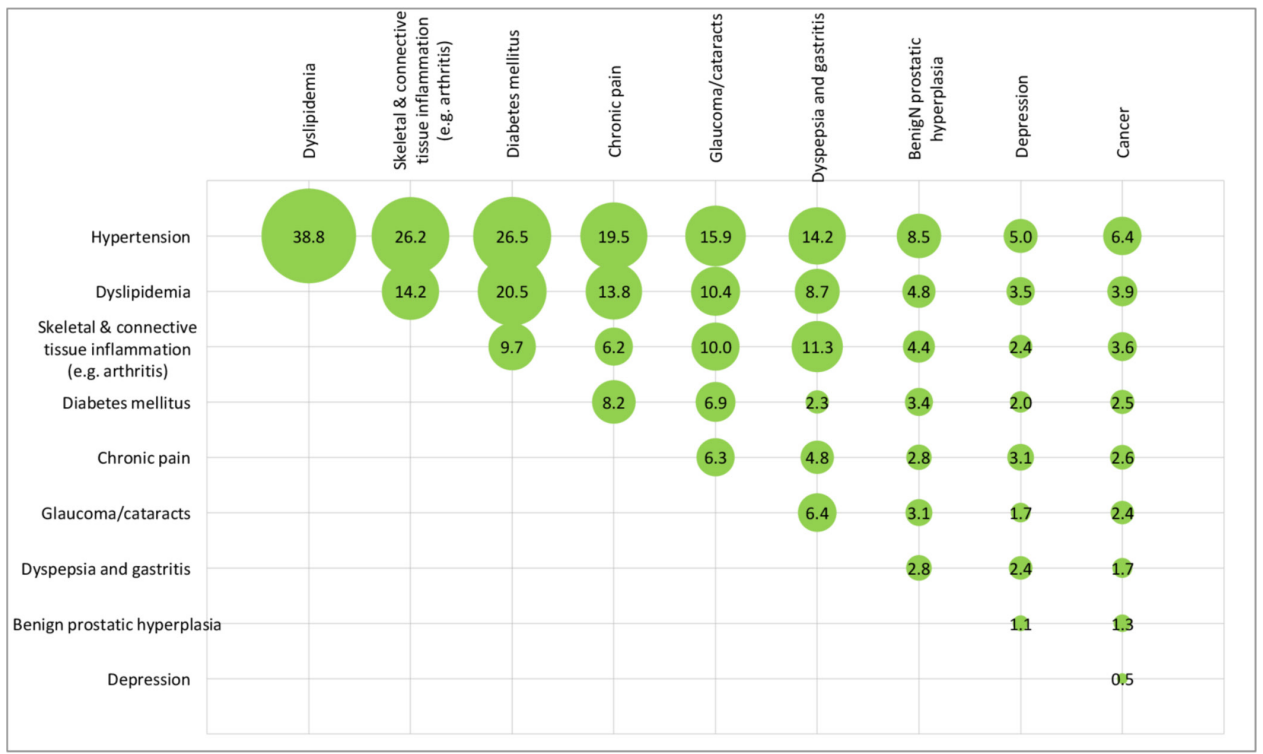

Figure 5 Weighted prevalence of the comorbidities of top 10 chronic conditions (out of 43 specific chronic conditions) among the 1077 elderly with multimorbidity (figures are weighted prevalence (\%)). 
physical, mental and social problems among all the study participants as well as some subgroups (eg, different age, gender, comorbidities). We are also initially planning cohort studies on factors associated with various health outcomes as well as quality of life and healthcare use. In addition, more explorations will be made to answer many other research questions based on hypotheses.

\section{Strengths and limitations}

This study has several strengths. First, this is one of the few aetiological studies on older adults being conducted in Asian primary care settings to examine physical, psychological and social problems accompanying with multimorbidity. Second, it prospectively covers a range of biopsychosocial factors, which are not included in other previous large-scale studies since plenty of them are derived from extracted medical or insurance records. Our findings suggest that people with multimorbidity have significant complex healthcare needs in physical, mental and social aspects such as obesity, multiple body pain, polypharmacy, depression, anxiety, insomnia and loneliness. The results suggested that a holistic approach that addresses general physical and functional domain of health, at the same time assessing and managing psychological and social problems is therefore needed in the care of older adults with multimorbidity. Services which are designed to cater for the complex needs of elder patients with multimorbidity from biopsychosocial perspectives are urgently needed. These service models should also be adapted and tested in local circumstances to maximise its efficacy. Furthermore, given the significant differences found between male and female patients in biopsychosocial aspects, future interventions may also need to take gender differences into account. Third, the results were weighted according to the census data to make the sample more representative of the general population. In general, the weighted results were similar to the unweighted results, and in consistency with results reported in the western populations. Fourth, because it contains linked electronic medical records, it will allow us to follow them up for public medical service use and mortality.

There are also several limitations. First, self-selection bias might still exist which was consistent with other similar studies, ${ }^{59}$ although we used weighting for adjustment, as not all variables were available for weighting such as education. Since only ambulatory adults who agreed to join were recruited and these usually are more likely to be female and those with higher educational level and higher self-motivation, and those who were housebound or institutionalised are less likely to have been included, we might have resulted in a relatively healthier and higher-functioning patients in primary care, and the real health status might be worse than what are reported in our study. Future studies may need to take measures to increase participation from male and vulnerable patients. Second, the sample size may limit examinations of potential interactions and factors associated with multimorbidity in some subgroups such as older men and patients with lower educational levels, or uncommon health problems. Third, we used a twostep assessment for some health indicators. While false negative reported rates of pain, insomnia and alcohol use were unlikely, there might be false negative rates for depression and anxiety as the specificity and sensitivity of PHQ-2 and GAD-2 were not 100\% (although results from meta-analytical reviews suggest they are reasonable to use in initial screening) ${ }^{49}{ }^{60}$ In addition, as PHQ-2 and GAD-2 are often used for screening with results in dichotomies (negative/positive), this might limit application of some statistical analysis such as using growth models in future longitudinal data. Fourth, for a few assessments, we only conducted them among a subgroup of participants, for example, PASE for physical activity among those patients with pain. Furthermore, some additional assessments such as meaning, sarcopenia, oral health were added at a later stage. So only subgroup data could be reported in this paper or analysed in the future when using these data.

Acknowledgements We would like to thank the General Outpatient Clinics (Lek Yuen, Ma On Shan, Shatin (Tai Wai), Yuen Chau Kok) and Shatin Rhenish Neighbourhood Elderly Centre for the support and help in recruitment. We also greatly thank all the patients who joined in the cohort.

Contributors SYSW conceived and supervised the study and revised the manuscript. DZ contributed to study design, analysed the data, prepared the draft and revised the manuscript. RWSS and CW contributed to the study design and implementation, and manuscript revisions. DZ contributed to data collection and manuscript revisions. SWM and MCJ contributed to manuscript revisions.

Funding The staff working on this cohort received funding from the Hong Kong Jockey Club Charities Trust.

Competing interests None declared.

Patient consent for publication Not required.

Provenance and peer review Not commissioned; externally peer reviewed.

Data availability statement Data are available on reasonable request. The authors warmly welcome collaborations for future research based on this study. For those who would like to request for the data or propose new assessments into the follow-up assessments, they can email to: (yeungshanwong@cuhk.edu.hk). For more information please see the website: http://cpcp.sphpc.cuhk.edu.hk/chi/.

Open access This is an open access article distributed in accordance with the Creative Commons Attribution Non Commercial (CC BY-NC 4.0) license, which permits others to distribute, remix, adapt, build upon this work non-commercially, and license their derivative works on different terms, provided the original work is properly cited, appropriate credit is given, any changes made indicated, and the use is non-commercial. See: http://creativecommons.org/licenses/by-nc/4.0/.

\section{ORCID iDs}

Dexing Zhang http://orcid.org/0000-0003-0073-4752

Regina Wing Shan Sit http://orcid.org/0000-0002-4717-7773

Marjorie C Johnston http://orcid.org/0000-0002-4660-3099

\section{REFERENCES}

1 Uijen AA, van de Lisdonk EH. Multimorbidity in primary care: prevalence and trend over the last 20 years. Eur J Gen Pract 2008;14:28-32.

2 Koné Pefoyo AJ, Bronskill SE, Gruneir A, et al. The increasing burden and complexity of multimorbidity. BMC Public Health 2015;15:415.

3 Violan C, Foguet-Boreu Q, Flores-Mateo G, et al. Prevalence, determinants and patterns of multimorbidity in primary care: a systematic review of observational studies. PLoS One 2014;9:e102149. 
4 Marengoni A, Angleman S, Melis R, et al. Aging with multimorbidity: a systematic review of the literature. Ageing Res Rev 2011;10:430-9.

5 Salisbury C. Multimorbidity: time for action rather than words. $\mathrm{Br} \mathrm{J}$ Gen Pract 2013:63:64-5.

6 Picco L, Achilla E, Abdin E, et al. Economic burden of multimorbidity among older adults: impact on healthcare and societal costs. BMC Health Serv Res 2016;16.

7 Glynn LG, Valderas JM, Healy P, et al. The prevalence of multimorbidity in primary care and its effect on health care utilization and cost. Fam Pract 2011;28:516-23.

8 World Health Organization. The global burden of disease: 2004 update. Geneva: World Health Organization, 2008.

9 Hay SI, Abajobir AA, Abate KH, et al. Global, regional, and national disability-adjusted life-years (DALYs) for 333 diseases and injuries and healthy life expectancy (HALE) for 195 countries and territories, 1990-2016: a systematic analysis for the global burden of disease study 2016. Lancet 2017;390:1260-344.

10 Salisbury C. Multimorbidity: redesigning health care for people who use it. The Lancet 2012;380:7-9.

11 Prados-Torres A, Poblador-Plou B, Gimeno-Miguel A, et al. Cohort profile: the epidemiology of chronic diseases and multimorbidity. The EpiChron cohort study. Int J Epidemiol 2018;47:382-4.

12 Hanlon $\mathrm{P}$, Nicholl BI, Jani BD, et al. Frailty and pre-frailty in middleaged and older adults and its association with multimorbidity and mortality: a prospective analysis of 493737 UK Biobank participants. 7, 2018: 3. e323-32.

13 Wei MY, Kabeto MU, Galecki AT, et al. Physical functioning decline and mortality in older adults with multimorbidity: joint modeling of longitudinal and survival data. J Gerontol A Biol Sci Med Sci 2019;74:226-32

14 Ibarra-Castillo C, Guisado-Clavero M, Violan-Fors C, et al. Survival in relation to multimorbidity patterns in older adults in primary care in Barcelona, Spain (2010-2014): a longitudinal study based on electronic health records. J Epidemiol Community Health 2018;72:185-92.

15 Guisado-Clavero M, Roso-Llorach A, López-Jimenez T, et al. Multimorbidity patterns in the elderly: a prospective cohort study with cluster analysis. BMC Geriatr 2018;18:16.

16 Katikireddi SV, Skivington $\mathrm{K}$, Leyland $\mathrm{AH}$, et al. The contribution of risk factors to socioeconomic inequalities in multimorbidity across the lifecourse: a longitudinal analysis of the Twenty-07 cohort. BMC Med 2017;15:152.

17 Lund Jensen N, Pedersen HS, Vestergaard M, et al. The impact of socioeconomic status and multimorbidity on mortality: a population-based cohort study. Clinical Epidemiology 2017;9:279-89.

18 Walker V, Perret-Guillaume C, Kesse-Guyot E, et al. Effect of multimorbidity on health-related quality of life in adults aged 55 years or older: results from the SU.VI.MAX 2 cohort. PLoS One 2016;11:e0169282.

19 Prior A, Fenger-Grøn M, Larsen KK, et al. The association between perceived stress and mortality among people with multimorbidity: a prospective population-based cohort study. Am J Epidemiol 2016;184:199-210.

20 Vos R, van den Akker M, Boesten J, et al. Trajectories of multimorbidity: exploring patterns of multimorbidity in patients with more than ten chronic health problems in life course. BMC Fam Pract 2015;16:2.

21 Farmer C, Fenu E, O'Flynn N, et al. Clinical assessment and management of multimorbidity: summary of NICE guidance. BMJ 2016;354:i4843.

22 Gunn JM, Ayton DR, Densley K, et al. The association between chronic illness, multimorbidity and depressive symptoms in an Australian primary care cohort. Soc Psychiatry Psychiatr Epidemiol 2012;47:175-84.

23 Mavaddat N, Valderas JM, van der Linde R, et al. Association of selfrated health with multimorbidity, chronic disease and psychosocial factors in a large middle-aged and older cohort from general practice: a cross-sectional study. BMC Fam Pract 2014;15.

24 Bock J-O, Luppa M, Brettschneider C, et al. Impact of depression on health care utilization and costs among Multimorbid patients - results from the MultiCare cohort study. PLoS One 2014;9:e91973.

24 Calderon-Larranaga A, Hernandez-Olivan P, Gonzalez-Rubio F, et al. Multimorbidity and weight loss in obese primary care patients: longitudinal study based on electronic healthcare records. . 3, 2015: 5. e006227.

27 France EF, Wyke S, Gunn JM, et al. Multimorbidity in primary care: a systematic review of prospective cohort studies. . 597 2012: 62. e297-307.

28 Boeckxstaens P, Vaes B, Legrand D, et al. The relationship of multimorbidity with disability and frailty in the oldest patients: a cross-sectional analysis of three measures of multimorbidity in the BELFRAIL cohort. . 1, 2015: 21. 39-44.

28 Brettschneider $\mathrm{C}$, Leicht $\mathrm{H}$, Bickel $\mathrm{H}$, et al. Relative impact of Multimorbid chronic conditions on health-related quality of life results from the MultiCare cohort study. PLoS One 2013;8:e66742.

29 Mercer SW, Gunn J, Wyke S. Improving the health of people with multimorbidity: the need for prospective cohort studies. London, England: SAGE Publications Sage UK, 2011.

30 France EF, Wyke S, Gunn JM, et al. Multimorbidity in primary care: a systematic review of prospective cohort studies. Br J Gen Pract 2012;62:e297-307.

31 Kuo RN, Lai M-S. The influence of socio-economic status and multimorbidity patterns on healthcare costs: a six-year follow-up under a universal healthcare system. Int J Equity Health 2013;12:69.

$31 \mathrm{Gu}$ J, Chao J, Chen W, et al. Multimorbidity and health-related quality of life among the community-dwelling elderly: a longitudinal study. , 2018: 74, 133-40.

34 Tromp J, Tay WT, Ouwerkerk W, et al. Multimorbidity in patients with heart failure from 11 Asian regions: a prospective cohort study using the ASIAN-HF registry. . 3, 2018: 15. e1002541.

34 Hughes LD, McMurdo MET, Guthrie B. Guidelines for people not for diseases: the challenges of applying UK clinical guidelines to people with multimorbidity. Age Ageing 2013;42:62-9.

35 Muth C, Beyer M, Fortin M, et al. Multimorbidity's research challenges and priorities from a clinical perspective: the case of ' $\mathrm{Mr}$ Curran'. Eur J Gen Pract 2014;20:139-47.

36 Fortin M, Lapointe L, Hudon C, et al. Multimorbidity is common to family practice: is it commonly researched? Can Fam Physician 2005;51:244-5

37 Kadam U. Redesigning the general practice consultation to improve care for patients with multimorbidity. BMJ 2012;345:e6202.

38 Smith SM, Soubhi H, Fortin M, et al. Managing patients with multimorbidity: systematic review of interventions in primary care and community settings. BMJ 2012;345:e5205.

39 Wallace E, Salisbury C, Guthrie B, et al. Managing patients with multimorbidity in primary care. BMJ 2015;350:h176.

40 The Government of Hong Kong Special Administrative Region (HKSAR). 2016 population By-census, 2018. Available: http:// wwwbycensus2016govhk/en/bc-mthtml [Accessed 31 Jul 2018].

41 Centre for Health Protection, Department of Health, The Governmenet of the Hong Kong Special Administrative Region. Life Expectancy at Birth (Male and Female), 1971 - 2017, 2018. Available: https://wwwchpgovhk/en/statistics/data/10/27/111html [Accessed 23 Jul 2018].

42 Hospital Authority, HKSAR. Hospital authority annual report 20162017. Available: http://wwwhaorghk/ho/corpcomm/AR201617/ ebook/en/mobile/indexhtml\#p=I [Accessed 23 Jul 2018].

43 Rosner B. Fundamentals of biostatistics. 6th edn. Pacific Grove, CA: Brooks/Cole, 2006.

44 Levine M, Ensom MHH. Post hoc power analysis: an idea whose time has passed?. Pharmacotherapy 2001;21:405-9.

45 Wang HHX, Wang JJ, Wong SYS, et al. Epidemiology of multimorbidity in China and implications for the healthcare system: cross-sectional survey among 162,464 community household residents in southern China. BMC Med 2014;12:188.

46 Barnett K, Mercer SW, Norbury M, et al. Epidemiology of multimorbidity and implications for health care, research, and medical education: a cross-sectional study. Lancet 2012;380:37-43.

47 Yu X, Stewart SM, Wong PTK, et al. Screening for depression with the patient health Questionnaire-2 (PHQ-2) among the general population in Hong Kong. J Affect Disord 2011;134:444-7.

48 Yu X, Tam WWS, Wong PTK, et al. The patient health Questionnaire-9 for measuring depressive symptoms among the general population in Hong Kong. Compr Psychiatry 2012;53:95-102.

49 Plummer F, Manea L, Trepel D, et al. Screening for anxiety disorders with the GAD-7 and GAD-2: a systematic review and diagnostic metaanalysis. Gen Hosp Psychiatry 2016;39:24-31.

50 Leung GTY, de Jong Gierveld J, Lam LCW. Validation of the Chinese translation of the 6-item de Jong Gierveld loneliness scale in elderly Chinese. Int Psychogeriatr 2008;20:1262-72.

51 Yu DSF, Doris S. Insomnia severity index: psychometric properties with Chinese community-dwelling older people. J Adv Nurs 2010;66:2350-9.

52 Ngai SPC, Cheung RTH, Lam PL, et al. Validation and reliability of the physical activity scale for the elderly in Chinese population. J Rehabil Med 2012;44:462-5.

53 Rolfson DB, Majumdar SR, Tsuyuki RT, et al. Validity and reliability of the Edmonton frail scale. Age Ageing 2006;35:526-9.

54 Zhang D, Chan DCC, Niu L, et al. Meaning and its association with Happiness, health and healthcare utilization: a cross-sectional study. J Affect Disord 2018;227:795-802. 
55 Malmstrom TK, Morley JE. SARC-F: a simple questionnaire to rapidly diagnose sarcopenia. J Am Med Dir Assoc 2013;14:531-2.

56 Woo J, Leung J, Morley JE. Validating the SARC-F: a suitable community screening tool for sarcopenia? J Am Med Dir Assoc 2014:15:630-4

57 Wong A, Xiong YY, Kwan PWL, et al. The validity, reliability and clinical utility of the Hong Kong Montreal cognitive assessment (HK$\mathrm{MoCA}$ ) in patients with cerebral small vessel disease. Dement Geriatr Cogn Disord 2009;28:81-7.
58 Wong ELY, Ramos-Goñi JM, Cheung AWL, et al. Assessing the use of a feedback module to model EQ-5D-5L health states values in Hong Kong. Patient 2018;11:235-47.

59 Silva Junior SHAda, Santos SM, Coeli CM, et al. Assessment of participation bias in cohort studies: systematic review and metaregression analysis. Cad Saúde Pública 2015;31:2259-74.

60 Mitchell AJ, Yadegarfar M, Gill J, et al. Case finding and screening clinical utility of the patient health questionnaire (PHQ-9 and PHQ-2) for depression in primary care: a diagnostic meta-analysis of 40 studies. BJPsych Open 2016;2:127-38. 